\title{
What makes a "successful" or "unsuccessful" discharge letter? Hospital clinician and General Practitioner assessments of the quality of discharge letters
}

Katharine Weetman ${ }^{1 *}$ D, Rachel Spencer ${ }^{1}$, Jeremy Dale ${ }^{1}$, Emma Scott $^{1}$ and Stephanie Schnurr ${ }^{2}$

\begin{abstract}
Background: Sharing information about hospital care with primary care in the form of a discharge summary is essential to patient safety. In the United Kingdom, although discharge summary targets on timeliness have been achieved, the quality of discharge summaries' content remains variable.
\end{abstract}

Methods: Mixed methods study in West Midlands, England with three parts: 1. General Practitioners (GPs) sampling discharge summaries they assessed to be "successful" or "unsuccessful" exemplars, 2. GPs commenting on the reasons for their letter assessment, and 3. surveying the hospital clinicians who wrote the sampled letters for their views. Letters were examined using content analysis; we coded 15 features (e.g. "diagnosis", "GP plan") based on relevant guidelines and standards. Free text comments were analysed using corpus linguistics, and survey data were analysed using descriptive statistics.

Results: Fifty-three GPs participated in selecting discharge letters; 46 clinicians responded to the hospital survey. There were statistically significant differences between "successful" and "unsuccessful" inpatient letters $(n=375)$ in relation to inclusion of the following elements: reason for admission (99.1\% vs 86.5\%); diagnosis (97.4\% vs 74.5\%), medication changes (61.5\% vs $48.9 \%)$; reasons for medication changes (32.1\% vs $18.4 \%$ ); hospital plan/actions (70.5\% vs $50.4 \%$ ); GP plan (69.7\% vs $53.2 \%$ ); information to patient (38.5\% vs $24.8 \%$ ); tests/procedures performed (97.0\% vs $74.5 \%)$, and test/examination results (96.2\% vs $77.3 \%)$. Unexplained acronyms and jargon were identified in the majority of the sample ( $\geq 70 \%$ of letters). Analysis of GP comments highlighted that the overall clarity of discharge letters is important for effective and safe care transitions and that they should be relevant, concise, and comprehensible. Hospital clinicians identified several barriers to producing "successful" letters, including: juniors writing letters, time limitations, writing letters retrospectively from patient notes, and template restrictions.

(Continued on next page)

\footnotetext{
* Correspondence: K.Weetman@warwick.ac.uk

'Unit of Academic Primary Care, Warwick Medical School, University of Warwick, Coventry, England CV4 7AL, UK

Full list of author information is available at the end of the article
} 


\begin{abstract}
(Continued from previous page)
Conclusions: The failure to uniformly implement national discharge letter guidance into practice is continuing to contribute to unsuccessful communication between hospital and general practice. While the study highlighted barriers to producing high quality discharge summaries which may be addressed through training and organisational initiatives, it also indicates a need for ongoing audit to ensure the quality of letters and so reduce patient risk at the point of hospital discharge.
\end{abstract}

Keywords: Discharge summaries, Discharge communication, Patient safety, Continuity of care, Discharge letters, Doctor and patient communication, Hospital discharge, Inter-professional communication

\section{Background}

Discharge from hospital is a high-risk healthcare event; risk of harm can originate in the secondary care setting [1] or the primary care setting [2,3], This is particularly well evidenced in relation to medications errors following discharge [4]. Sharing accurate, relevant information about the care received in hospital with primary care in the form of a discharge summary is essential to patient safety. This process inherently involves interprofessional communication which has been previously suggested as an area that requires improvement $[5,6]$. Poor discharge communication is an important cause of adverse events in medical defence organisation data [7] and incident reports from primary care [8-10]. Two inter-related elements are at play: speed of information transfer and quality of information transferred. International evidence suggests that discharge letters are unsatisfactory for a number of reasons including: incomplete and insufficient information [11-13], unclear follow up plans [12, 14, 15], letter inaccuracies [16], delayed letter delivery [12, 17, 18], inadequate medication information $[19,20]$, lack of patient-centredness (e.g. letter dense with jargon) [12, 21, 22] and general communication gaps leading to adverse events such as patient readmissions [23, 24].

In the United Kingdom (UK), hospitals have been required to use electronic discharge summaries since 2015, and the benefits of such summaries are well established [25]. Hospitals are now required to produce summaries within $24 \mathrm{~h}$ [26]. Our previous study [2], conducted in 2016, in general practices in three different areas of the UK, shows that summaries arrive and are uploaded to General Practitioner (GP) systems in a time efficient manner (median of two days from discharge). Although targets on timeliness appear to have been achieved, the quality of discharge summaries' content remains less certain and there is now a need to focus on this as a route to improved patient safety during care transitions.

The Discharge Communication Study [27] (of which this research is a part) investigated ways of improving the content and processes surrounding discharge letters. Results relating to GP interviews contextualising elements of successful letters [28], and patient interviews (which investigate patient-provider communication) [29] have already been published elsewhere. In this paper we report clinicians' opinions on the quality of discharge letters which are crucial to understanding how to improve inter-professional communication at the time of discharge. We investigated quality from the perspectives of 'instigator' (hospital) and 'receiver' (primary care) through surveys and discharge letter analysis; this is important given that GPs manage patient care when they are discharged back to the community, as is comparing these views with that of the hospital clinician who is responsible for managing patient care in hospital and writing the discharge letter. This paper describes from hospital clinician and GP perspectives what makes a "successful" or "unsuccessful" discharge letter. The research questions were:

1. What do hospital clinicians and GPs judge to be the features and key content-items of "successful" discharge letters?

2. What do hospital clinicians view as barriers to producing "successful" or high-quality discharge letters?

\section{Methods \\ Recruitment and data collection}

To explore what makes a "successful" or "unsuccessful" discharge letter, our mixed methods study gathered data across the West Midlands, England, from three sources: 1. discharge letters sampled by GPs as reflecting "successful" or "unsuccessful" exemplars, 2. comments by the GPs to explain their letter gradings, and 3. a hospital clinician survey.

GP recruitment and discharge letter sampling took place between August 2017 and April 2018. As stated in our published study protocol [27], "the study aimed to recruit 30-50 GPs across 15 practices, with a target of 23 GPs per practice" (p.5). Furthermore, the study protocol [27] describes that participating GPs were asked to select 14-24 recent ( $<3$ weeks) discharge letters which they assessed to be "successful" or "unsuccessful" exemplars. They were asked to select these from letters 
relating to adult (18+ years) patients discharged from an NHS hospital in Warwickshire, Coventry, Rugby, Herefordshire or Worcestershire following an episode of inpatient or outpatient care, excluding discharge letters from mental health services or related to patients who lacked capacity to consent [27] (for further details and full justification of the inclusion and exclusion criteria, see our study protocol [27]). GP letter selection identified potential participants for all subsequent phases relating to the Discharge Communication Study [27], including patients eligible for interview (these results are published separately [29]).

There were no set criteria for letter gradings of "successful" and "unsuccessful" as it was purposefully intended to reflect each participating GP's individual interpretation and experiences of whether the letter communicated necessary, important discharge information [27]. The GPs were asked to complete a selection template (additional file 1) to record their letter gradings and comments on their reasons for the letter categorisations [27]. As stated in our protocol [27], "GP practice staff redacted the letters of patient identifiable information" (p.5). After redaction [27], letters were transferred to the research team for analysis of the GP comments as well as assessment of the letters themselves through content analysis (see analysis section below).

Hospital clinicians who were identified as having written a letter included in those sampled by the GPs were invited to take part in a survey (see additional file 2). This asked them to assess the letter they wrote in relation to different content items (e.g. diagnosis information) and for different audiences (e.g. GP or patient). The survey was open from May to September 2018. Survey packs were sent by post or distributed by internal mail within the hospital [27]; packs contained an invitation letter explaining why they had been selected, a participant information sheet, the survey, and a redacted copy of the sampled discharge letter [27]. Where a clinician had been included in the sample on more than one occasion, they only received a survey pack related to one letter that had been included in the sample; letters were prioritised by whether the patient and GP had taken part in interviews (see protocol [27] for further details of this letter and case matching process). The invitation letter stated that completing and returning a survey indicated consent. The survey asked respondents to select numerical ratings on a "semantic differential" [30, 31] scale from 1 to 9 , with 1 being 'low' and 9 being 'high'; each end of the scale featured bipolar evaluative adjectival phrases e.g. "uninformative/ informative". Adjectives were selected for measuring varying dimensions of beliefs toward the letter quality. To encourage participation the survey was kept relatively short; 14 of the questions were closed with one open question at the end of the survey (see additional file 2).

\section{Analysis}

\section{Discharge letter content analysis}

Discharge letters were analysed using content analysis [32-34] which is a systematic approach to qualitative textual data utilising coding techniques in order to deduce findings [32, 34]. Our content analysis aimed to examine possible associations between the content of letters and GP quality gradings to address the research questions. The alternative (H1) and null hypothesis (H0) are below:

H1: There is an association between [letter content features] and GP letter gradings.

H0: There is no association between [letter content features] and GP letter gradings.

Discharge letter standards [35-38] were used to structure assessment of the quality of the letter sample in terms of content components (e.g. diagnosis). Guidelines released after letter sampling [39] were not used due to unfairness in evaluating letters against guidelines not yet published at the time of letter production (e.g. 2019 eDischarge standards [40]). Content items from guidelines were selected and synthesised with respect to the research questions. Coding categories (e.g. procedures performed) were primarily based around core clinical elements (e.g. investigation results) and informational needs of patients (e.g. jargon explained) and GPs (e.g. GP plan). Letters were coded as to whether they contained content components and thus adhered to guidelines and standards.

The initial coding system for content analysis had 20 categories; this was piloted with a $5 \%$ sample coded independently by KW and JD to assess coding reliability. Inter-coder agreement was generally satisfactory (Table 1 ) $(k>0.8)$ [41]; the median across scores was 0.94. Two categories had unsatisfactory agreement: "reasons for medication" $(\mathrm{k}=.791)$ and "medical jargon" $(\mathrm{k}=.584)$. Discussion revealed differences in coding of implicit and explicit reasons for medication and whether jargon was explained from the lay or expert clinical perspective. These issues were resolved with minor revisions to the categorisation system (merging two categories, and removal of four categories due to category coding overlap). The first author coded the remaining $95 \%$ of the sample; difficult cases were discussed with the team. The final content analysis framework contained 15 categories (see additional file 3 for full list) which included:

1. Discharging physician details (name and role of discharging physician)

2. Clinical summary elements (reason for admission, diagnosis, procedures/investigations performed and results)

3. Any pending hospital plans or actions such as follow up in outpatient clinic 
Table 1 Results of inter-coder agreement for pilot content coding

\begin{tabular}{|c|c|}
\hline Categorisation heading for coding & Kappa agreement measure \\
\hline Discharging speciality/department & $.881(p<0.001)$ \\
\hline Discharging consultant & $.940(p<0.001)$ \\
\hline Reason for admission & $.940(p<0.001)$ \\
\hline Diagnosis & $.940(p<0.001)$ \\
\hline Procedures and investigations performed & $.940(p<0.001)$ \\
\hline Clinical summary & $.970(p<0.001)$ \\
\hline Investigation results & $.881(p<0.001)$ \\
\hline Examination findings & $.851(p<0.001)$ \\
\hline Medication name(s) & $.970(p<0.001)$ \\
\hline Medication dose and frequency & $.970(p<0.001)$ \\
\hline Reasons for medication & $.791(p<0.001)$ \\
\hline Medication recommendations & $.911(p<0.001)$ \\
\hline Medication changes & $.910(p<0.001)$ \\
\hline Reasons for medication changes & $.881(p<0.001)$ \\
\hline Investigations/procedures/appointments requested of where results are pending & $.940(p<0.001)$ \\
\hline Patient's and carer's concerns, expectations and wishes & $1.00(p<0.001)$ \\
\hline Information and advice given to patient & $.940(p<0.001)$ \\
\hline Plan and requested actions/follow up & $.911(p<0.001)$ \\
\hline Acronyms (unexplained) & $.940(p<0.001)$ \\
\hline Medical jargon (unexplained) & $.584(p<0.001)$ \\
\hline
\end{tabular}

4. Medication information (name and dosing, details of changes and reasons)

5. GP plan (follow up, actions and management recommendations)

6. Details of patient wishes/concerns as well as information provided to patient

7. Elements pertaining to letter content style (e.g. whether acronyms explained).

Following piloting it was decided that the content coding should focus solely on the sampled inpatient letters. This was intended to increase the homogeneity of the sample.

"Successful" and "unsuccessful" coding results for the letters were quantitatively compared using Chi-square [42] $(p<0.05)$ in order to test hypotheses that there are content feature differences between GP-assessed "successful" and "unsuccessful" letters [27]. As the crosstabulations for feature coding were $2 \times 2$, Yates' correction was used [43]. We also compared Yates and Fishers corrections for all chi-square results; there were no significant differences.

\section{Discharge letter comment analysis}

Corpus linguistics $[44,45]$ is the study of collections of texts or corpora [46] and was used to analyse the GP comments relating to their quality assessment of sampled discharge letters. Corpus linguistics focuses on analysing patterns [47] and has previously successfully been applied to comment data within healthcare [48, 49]. Frequency and relative frequency results were compared between the "successful" and "unsuccessful" comment sub-corpora in order to expound patterns of relevance to the research questions. Concordance software Antconc [50] was used for compiling the corpus and generating outputs.

\section{Hospital clinician survey analysis}

Survey results were analysed using descriptive statistics in Statistical Package for the Social Sciences (SPSS). Tests were nonparametric $[51,52]$ to avoid making distributional assumptions about the survey responses [43]. Hospital clinician free text comments were narratively overviewed using a rudimentary thematic analysis [53, 54] by KW whereby comments were read, re-read, and then annotated for ideas and concepts relating to the research questions; these were then reviewed and iteratively refined through discussion with other members of the research team (ES, JD, SS). During this process, "themes" began to emerge which were iteratively refined.

Agreement analyses using descriptive percentages were also undertaken to compare the GP and hospital letter ratings. Kappa measures $[55,56]$ were run to look at the proportion of agreement between the GP 
and hospital respondents. GP gradings were binary (successful/unsuccessful) while HP gradings were on an interval scale 1-9. Consequently, as the kappa test requires and assumes two categorical variables with equal categories [43], HP gradings were recoded into unsuccessful (assessment scores 1-5) and successful (scores 6-9).

\section{Results}

\section{Recruitment and data collection}

The study recruited 53 GPs across 18 practices with a median of 3 GPs per practice; range 1-8 GPs (see Fig. 1 for flowchart of data collection and recruitment). There was a median selection of 10 letters per GP, leading to a total sample of 489 discharge letters. 375 (76.7\%) of these were inpatient discharge summaries; 234 (62.4\%) were graded "successful" and 141 (37.6\%) "unsuccessful". The letters mainly related to patient care from four hospital trusts, and spanned 33 specialties with over 300 different reasons for care. A summary of GP practice and letter characteristics is in Table 2.

Hospital clinicians eligible to participate in the survey were defined as the authors of the discharge letters. There were some letters with no named author or author name illegible, or where the author had left the trust. As a result, 308 doctors, nurses and allied health professionals were invited to take part in the survey, leading to responses from 46 hospital clinicians (response rate $=14.9 \%$, see Fig. 1). A summary of responder characteristics is found in Table 3. Response rates ranged between hospital sites (5.4-33.3\%). Variation was seen in age (24-60 years) and experience of respondents (qualifying year 1982-2017) although a large portion of surveys were completed by consultants $(n=19,41.3 \%)$. Gender was self-described and in $74 \%$ of surveys, this information was optionally provided (15 female - 44.1\%, 19 male - 55.9\%). Interesting, but not statistically significant, trends were observed: junior doctors $(n=9)$ produced a low proportion of successful letters (22.2\%), nurses/Advanced Clinical Practitioners (ACPs) $(n=10)$ produced a high proportion of successful letters (80.0\%), and Acute Medicine $(n=5)$ and Cardiology $(n=$ 5) had high weightings of successful letters (80.0 and $100.0 \%$ respectively).

\section{Features of successful discharge letters}

Content analysis revealed that no feature was present in all discharge letters (Table 4 ). Highly frequent $(\geq 80 \%$ of letters) content components were: reason for admission (94.4\%), diagnosis (88.8\%), tests/procedures performed (88.5\%), investigation results/examination findings (89.1\%), discharging physician name and role (84.0\%), medication names $(82.4 \%)$, medication dose and frequency $(82.1 \%)$. Somewhat frequent (51-80\% of letters) content components were: GP plan (63.5\%), hospital plan (62.9\%), medication changes (56.8\%). For the following features, there were statistically significant differences between GP-assessed "successful" and "unsuccessful" letters (see Table 5):

- Reason for admission (99.1\% successful, $86.5 \%$ unsuccessful, $\left.X^{2}=24.176, p<0.001\right)$

- Diagnosis (97.4\% successful, $74.5 \%$ unsuccessful, $\left.X^{2}=44.386, p<0.001\right)$

- Medication changes (61.5\% successful, $48.9 \%$ unsuccessful, $X^{2}=5.193, p=0.023$ )

- Reasons for medication changes (32.1\% successful, $18.4 \%$ unsuccessful, $\left.X^{2}=7.606, p=0.006\right)$

- Hospital plan/actions (70.5\% successful, $50.4 \%$ unsuccessful, $\left.X^{2}=14.475, p<0.001\right)$

- GP plan (69.7\% successful, $53.2 \%$ unsuccessful, $X^{2}=$ 9.591, $p=0.002)$

- Information to patient (38.5\% successful, $24.8 \%$ unsuccessful, $X^{2}=6.764, p=0.009$ )

- Tests/procedures performed (97.0\% successful, $74.5 \%$ unsuccessful, $\left.X^{2}=41.841, p<0.001\right)$

- Test/examination results (96.2\% successful, $77.3 \%$ unsuccessful, $\left.X^{2}=30.194, p<0.001\right)$.

The GP comment corpus $(n=375)$ comprised 4804 words and was divided into two sub-corpora formed of 189 (50.4\%) "successful" graded letter comments (2093 words) and 186 (49.6\%) "unsuccessful" graded letter comments (2711 words). The 25 most frequent content words (excluding functional words e.g. to/of/and) are in Table 6. As the number of comments was felt to be a manageable number, a saturation point [48] was not required and all comments were examined. A summary of qualitative findings relating to GP comments is found in Table 7. Notably, the most frequent word in the "successful" comment sub-corpus was an evaluative adjective "clear" ( $n=157)$ which featured in $115 / 189$ "successful" comments (dispersion - 60.8\%) and had almost triple the number of hits than the second most frequent word "follow" $(n=53)$. Participants drew on this adjective to convey that features needed to be "clear" i.e. easy to find, appropriate, and comprehensible in terms of language (not uncommon acronym) and content. Common collocates of "clear" were "diagnosis" (Log-likelihood (LL) = $163)$ and "plan" ( $L L=175.2)$. This highlights the importance of the "clearness" of these items to GPs which was exemplified in the results.

Hospital survey respondents generally rated their letters highly; the median for all questions was either 7 or 8 (scale rating 1-9) (see additional file 4).

Features of unsuccessful discharge letters

Only one summary had all 15 content components $(0.3 \%)$. No single component was present in every 


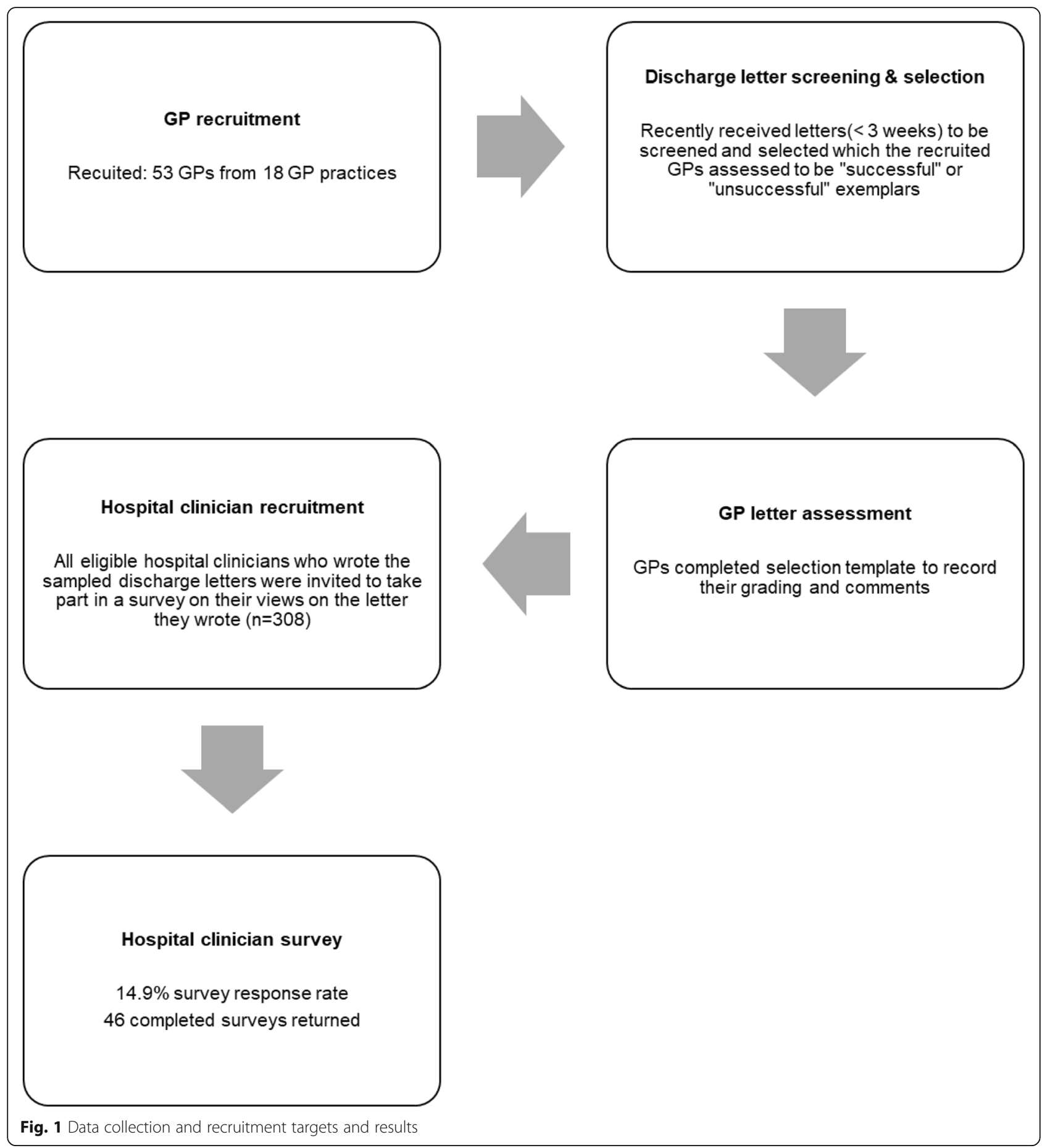

summary despite the ubiquity of some of these components (e.g. reason for admission). The following components were infrequent $(20-50 \%)$ within the sample: information given to patient (33.3\%), reasons for medication changes (26.9\%), explained medical jargon (23.5\%). Two components were rarely present $(<20 \%$ of letters): explained acronyms (18.7\%), patient concerns/wishes (8.3\%). Unexplained acronyms were found in $81.3 \%$ of letters although differences between successful and unsuccessful letters were not significant $\left(X^{2}=3.482, p=\right.$ $0.062)$. The feature of unexplained medical jargon was present in $76.5 \%$ of letters including $84.4 \%$ of unsuccessful letters $\left(X^{2}=7.095, p=0.008\right)$.

For the 44 letters where both GP and HP gradings were available, $24(54.5 \%)$ were rated as successful by the GPs and $36(81.8 \%)$ were rated as successful by the 
Table 2 Summary of inpatient discharge letter sample and GP practice characteristics

\begin{tabular}{|c|c|c|}
\hline \multirow[t]{2}{*}{ Demographics and characteristics } & \multicolumn{2}{|c|}{ Inpatient discharge letter sample $(n=375)$} \\
\hline & Group & Frequency (\%) \\
\hline \multirow[t]{3}{*}{ GP letter grading } & Successful & $234(62.4 \%)$ \\
\hline & Unsuccessful & $141(37.6 \%)$ \\
\hline & Total & $375(100 \%)$ \\
\hline \multirow[t]{3}{*}{ GP practice sizes } & Small (<5000 patients) & $1(5.6 \%)$ \\
\hline & Medium (5-10,000 patients) & $11(61.1 \%)$ \\
\hline & Large (10,000+ patients) & $6(33.3 \%)$ \\
\hline \multirow[t]{35}{*}{ Discharge speciality } & missing & $88(23.5 \%)$ \\
\hline & Accident \& Emergency & $10(2.7 \%)$ \\
\hline & Acute Medicine & $7(1.9 \%)$ \\
\hline & Ambulatory care & $2(0.5 \%)$ \\
\hline & Acute Medical Unit & $2(0.5 \%)$ \\
\hline & Breast Surgery & $2(0.5 \%)$ \\
\hline & Cardiology & $22(5.9 \%)$ \\
\hline & Cardiothoracic Surgery & 7 (1.9\%) \\
\hline & Clinical Haematology & $6(1.6 \%)$ \\
\hline & Colorectal Surgery & $8(2.1 \%)$ \\
\hline & Diabetic Medicine & $5(1.3 \%)$ \\
\hline & Endocrinology & $6(1.6 \%)$ \\
\hline & Ear Nose and Throat & $5(1.3 \%)$ \\
\hline & Fetal Medicine & $1(0.3 \%)$ \\
\hline & Gastroenterology & $4(1.1 \%)$ \\
\hline & Gastrointestinal Surgery & $6(1.6 \%)$ \\
\hline & General Medicine & $32(8.5 \%)$ \\
\hline & General Surgery & $26(6.9 \%)$ \\
\hline & Geriatric Medicine & $15(4.0 \%)$ \\
\hline & Infectious diseases & $3(0.8 \%)$ \\
\hline & Maxillo-facial surgery & $2(0.5 \%)$ \\
\hline & Nephrology & $10(2.7 \%)$ \\
\hline & Neurology & $2(0.5 \%)$ \\
\hline & Neurosurgery & $3(0.8 \%)$ \\
\hline & Obstetrics \& Gynaecology & $22(5.9 \%)$ \\
\hline & Oncology & $3(0.8 \%)$ \\
\hline & Ophthalmology & $1(0.3 \%)$ \\
\hline & Pancreatic Surgery & $1(0.3 \%)$ \\
\hline & Plastic Surgery & $1(0.3 \%)$ \\
\hline & Respiratory Medicine & $21(5.6 \%)$ \\
\hline & Stroke Medicine & $7(1.9 \%)$ \\
\hline & Trauma \& Orthopaedics & $16(4.3 \%)$ \\
\hline & Urology & $21(5.6 \%)$ \\
\hline & Vascular Surgery & $8(2.1 \%)$ \\
\hline & Total & $375(100.0 \%)$ \\
\hline \multirow[t]{2}{*}{ Letter format } & combination & $14(3.7 \%)$ \\
\hline & handwritten & $5(1.3 \%)$ \\
\hline
\end{tabular}


Table 2 Summary of inpatient discharge letter sample and GP practice characteristics (Continued)

\begin{tabular}{|c|c|c|}
\hline Demographics and characteristics & Inpatient discharge letter sample $(n=375)$ & \\
\hline & typed & $356(94.9 \%)$ \\
\hline & Total & $375(100.0 \%)$ \\
\hline \multirow[t]{4}{*}{ Sex of patient } & missing & $181(48.3 \%)$ \\
\hline & Female & $94(25.1 \%)$ \\
\hline & Male & $100(26.7 \%)$ \\
\hline & Total & $375(100.0 \%)$ \\
\hline \multirow[t]{3}{*}{ Age of patient } & Range & $20-96$ \\
\hline & Median & 64 \\
\hline & IQR & 38,77 \\
\hline \multirow[t]{6}{*}{ Role of signing physician } & Nurse/ACP & $24(6.4 \%)$ \\
\hline & Junior Doctor & $177(47.2 \%)$ \\
\hline & Speciality Trainee/ Core Trainee/ Registrar & $80(21.3 \%)$ \\
\hline & Consultant & $14(3.7 \%)$ \\
\hline & Other or unclear & $80(21.3 \%)$ \\
\hline & Total & $375(100.0 \%)$ \\
\hline
\end{tabular}

HPs. There was overall agreement on letter successfulness in 24 cases (54.5\%); this included 20 cases that were assessed as successful and four cases that were rated as unsuccessful. For 20 (45.5\%) letters there was disagreement on the quality of the letter; this comprised 16 where the letter was graded successful by the hospital clinician but unsuccessful by the GP and the reverse occurred for 4 cases. These results were not statistically significant $(\mathrm{k}=0.035, p=0.775)$.

Question 15 in the hospital survey provided a free text space for respondents to comment further or provide reasons for their answers. Thirty-two respondents (69.6\%) answered this question, answers generally consisted of 2-3 sentences ranging from 15 to 101 words. Several respondents identified barriers to providing successful discharge letters:

1. Juniors writing letters ("These pro forma letters are often wrong, delegated to most junior doctors who may not even be on my team." Consultant)

2. Time restrictions ("A good detailed discharge summary depends on the amount of time the doctor has to write it. At a busy? night shift, this is very difficult." Junior doctor) ("Often we have short of doctors on the ward and we cannot spend too much time on discharge letters." Junior doctor)

3. Writing letters from patient notes and/or where patient not known to hospital clinician ("We often have to retrospectively completed EDs [sic] after the patient is discharged - having only medical notes to go by - info can be limited." Nurse/ACP)

4. Issues with computer system/template ("Our discharge letters are autogenerated from diagnostic and treatment PBR codes [sic]. We have no individual input into their quality/content" Consultant) ("There is a limit to "words" what you can put [sic] on certain "text boxes" hence sometimes whole information can't be put on discharge summaries" Consultant)

5. Lack of support and training ("I feel perhaps further support from senior clinicians early on in the [TRAI NING] will enable more concise discharge letters and enable [HOSPITAL ROLE] to have more confidence in completing them" Nurse/ACP).

\section{Discussion \\ Key findings}

GP-graded "successful" letters generally adhered to national standards whereas "unsuccessful" letters did not. Successful letters more frequently included a range of elements, with statistically significant differences in the inclusion of details about reason for admission, diagnosis, medication changes, reasons for medication changes, hospital plan/actions, GP plan, information to patient, tests/procedures performed, and test/examination results. Hospital clinicians tended to rate their letters as being of greater quality than was evident from the assessment made by GPs. Hospital clinicians identified several barriers to producing "successful" letters, such as: juniors writing letters, time limitations, writing letters from patient notes retrospectively, and restrictions of electronic templates. Such barriers need addressing through increased training and organisational initiatives. Relatedly, the results demonstrated that the discharge letters within the sample were often incomplete. 
Table 3 Summary of hospital respondents and relating discharge letter characteristics

\begin{tabular}{|c|c|c|}
\hline \multirow[t]{2}{*}{ Demographics and characteristics } & \multicolumn{2}{|l|}{ Sample results } \\
\hline & Group & Frequency (\%) \\
\hline \multirow[t]{3}{*}{ GP letter grading } & Successful & $25(54.3 \%)$ \\
\hline & Unsuccessful & $21(45.7 \%)$ \\
\hline & Total & $46(100 \%)$ \\
\hline \multirow[t]{19}{*}{ Discharge speciality } & None specified & $4(8.7 \%)$ \\
\hline & Accident \& Emergency & $4(8.7 \%)$ \\
\hline & Acute Medicine & $5(10.9 \%)$ \\
\hline & Ambulatory care & $1(2.2 \%)$ \\
\hline & Cardiology & $5(10.9 \%)$ \\
\hline & Cardiothoracic Surgery & $2(4.3 \%)$ \\
\hline & Care of the Elderly & $2(4.3 \%)$ \\
\hline & Colorectal Surgery & $1(2.2 \%)$ \\
\hline & Day Surgery & $2(4.3 \%)$ \\
\hline & Ear Nose and Throat & $3(6.5 \%)$ \\
\hline & General Medicine & $2(4.3 \%)$ \\
\hline & General Surgery & $3(6.5 \%)$ \\
\hline & Gynaecology & $2(4.3 \%)$ \\
\hline & Pain service & $1(2.2 \%)$ \\
\hline & Plastics & $1(2.2 \%)$ \\
\hline & Respiratory & $1(2.2 \%)$ \\
\hline & Trauma \& Orthopaedics & $4(8.7 \%)$ \\
\hline & Urology & $3(6.5 \%)$ \\
\hline & Total & $46(100.0 \%)$ \\
\hline \multirow[t]{4}{*}{ Gender of hospital respondent } & Missing & $12(26.1 \%)$ \\
\hline & Female & $15(32.6 \%)$ \\
\hline & Male & $19(41.3 \%)$ \\
\hline & Total & $46(100.0 \%)$ \\
\hline \multirow[t]{6}{*}{ Age of hospital respondent } & Missing & $12(26.1 \%)$ \\
\hline & $21-30$ & $9(19.6 \%)$ \\
\hline & $31-40$ & $10(21.7 \%)$ \\
\hline & $41-50$ & $9(19.6 \%)$ \\
\hline & $51-60$ & $6(13.0 \%)$ \\
\hline & Total & $46(100.0 \%)$ \\
\hline \multirow[t]{6}{*}{ Role of signing physician } & Other & $1(2.2 \%)$ \\
\hline & Nurse/ACP & $10(21.7 \%)$ \\
\hline & Junior Doctor & $9(19.6 \%)$ \\
\hline & Speciality Trainee/ Core Trainee/ Registrar & $7(15.2 \%)$ \\
\hline & Consultant & $19(41.3 \%)$ \\
\hline & Total & $46(100.0 \%)$ \\
\hline \multirow[t]{5}{*}{ Ethnicity of hospital respondent } & Missing & $14(30.4 \%)$ \\
\hline & African & $2(4.3 \%)$ \\
\hline & Asian & $4(8.7 \%)$ \\
\hline & British & $5(10.9 \%)$ \\
\hline & White & 9 (19.6\%) \\
\hline
\end{tabular}


Table 3 Summary of hospital respondents and relating discharge letter characteristics (Continued)

\begin{tabular}{|c|c|c|}
\hline \multirow[t]{2}{*}{ Demographics and characteristics } & \multicolumn{2}{|l|}{ Sample results } \\
\hline & Group & Frequency (\%) \\
\hline & White British & $11(23.9 \%)$ \\
\hline & Irish & $1(2.2 \%)$ \\
\hline & Total & $46(100.0 \%)$ \\
\hline \multirow[t]{3}{*}{ Training location of hospital respondent } & Internationally & $6(13.0 \%)$ \\
\hline & Nationally (UK) & $40(87.0 \%)$ \\
\hline & Total & $46(100.0 \%)$ \\
\hline \multirow[t]{5}{*}{ Hospital respondent year qualified } & $1981-1990$ & $7(15.2 \%)$ \\
\hline & $1991-2000$ & $12(26.1 \%)$ \\
\hline & $2001-2010$ & $12(26.1 \%)$ \\
\hline & 2011-2017 & $15(32.6 \%)$ \\
\hline & Total & $46(100.0 \%)$ \\
\hline \multirow[t]{6}{*}{ Religion of hospital respondent } & Missing & $27(58.7 \%)$ \\
\hline & Atheist & $3(6.5 \%)$ \\
\hline & Christian & $11(23.9 \%)$ \\
\hline & Hindu & $3(6.5 \%)$ \\
\hline & Islam & $2(4.3 \%)$ \\
\hline & Total & $46(100.0 \%)$ \\
\hline
\end{tabular}

Corpus linguistic analysis of the GP letter comments led to insights on GPs' views on discharge letters (see Table 7 for summary). Importantly, "clear" was ranked top in the "successful" comment sub-corpus, which suggests that clarity may be one of the most important elements of a "successful" letter from a GP perspective. This highlights that it is important for discharge letters to be comprehensible, relevant, and concise. Letters that
GPs rated "successful" tended to have particular content features: reason for admission, diagnosis, follow up and management plan, medication changes and reasons, GP actions, treatment, investigations and results, discharging physician details, and information provided to the patient. "Unsuccessful" letters (37.6\% of sample) either omitted some of the above components or they were unclear, as detailed in Table 7. Moreover, GP comments

Table 4 Descriptive statistics for inpatient discharge letters content coding $(n=375)$

\begin{tabular}{lll}
\hline Content feature & Feature presence (yes) & Feature absence (no) \\
\hline 1. Discharging physician (name and role) & $84.0 \%$ & $16.0 \%$ \\
2. Reason for admission & $94.4 \%$ & $5.6 \%$ \\
3. Diagnosis & $88.8 \%$ & $11.2 \%$ \\
4. Tests/procedures performed & $88.5 \%$ & $11.5 \%$ \\
5. Investigation results/examination findings & $89.1 \%$ & $10.9 \%$ \\
6. Medication names & $82.4 \%$ & $17.6 \%$ \\
7. Medication dose and frequency & $82.1 \%$ & $17.9 \%$ \\
8. Medication changes & $56.8 \%$ & $43.2 \%$ \\
9. Reasons for medication changes & $26.9 \%$ & $73.1 \%$ \\
10. Hospital plan (pending actions e.g. outpatient appointment) & $62.9 \%$ & $37.1 \%$ \\
11. Patient concerns/wishes & $8.3 \%$ & $91.7 \%$ \\
12. Information to patient & $33.3 \%$ & $66.7 \%$ \\
13. GP plan (actions/management) & $63.5 \%$ & $36.5 \%$ \\
14. Acronyms (unexplained) & $81.3 \%$ & $18.7 \%$ \\
15. Medical jargon (unexplained) & $76.5 \%$ & $23.5 \%$ \\
\hline
\end{tabular}


Table 5 Summary of statistical findings for letter content features against GP gradings

\begin{tabular}{|c|c|c|c|c|c|c|c|c|}
\hline $\begin{array}{l}\text { Content feature (independent } \\
\text { variable) }\end{array}$ & $\begin{array}{l}\text { Present in successful } \\
\text { letters }\end{array}$ & $\begin{array}{l}\text { Present in unsuccessful } \\
\text { letters }\end{array}$ & Test & Df.* & $n$ & $\mathrm{x}^{2}$ & $\begin{array}{l}\text { Effect size -phi } \\
\text { coefficient }\end{array}$ & $\begin{array}{l}P \\
\text { value }\end{array}$ \\
\hline $\begin{array}{l}\text { Discharging physician (name \& } \\
\text { role) }\end{array}$ & $86.8 \%$ & $79.4 \%$ & $x^{2}$ & 1 & 375 & 2.984 & -.097 & 0.084 \\
\hline Reason for admission & $99.1 \%$ & $86.5 \%$ & $x^{2}$ & 1 & 375 & 24.176 & -.266 & $\begin{array}{l}< \\
0.001\end{array}$ \\
\hline Diagnosis & $97.4 \%$ & $74.5 \%$ & $x^{2}$ & 1 & 375 & 44.386 & -.353 & $\begin{array}{l}< \\
0.001\end{array}$ \\
\hline Tests/procedures performed & $97.0 \%$ & $74.5 \%$ & $x^{2}$ & 1 & 375 & 41.841 & -.343 & $\begin{array}{l}< \\
0.001\end{array}$ \\
\hline Investigation results & $96.2 \%$ & $77.3 \%$ & $x^{2}$ & 1 & 375 & 30.194 & -.293 & $\begin{array}{l}< \\
0.001\end{array}$ \\
\hline Medication names & $84.6 \%$ & $78.7 \%$ & $x^{2}$ & 1 & 375 & 1.719 & -.075 & 0.190 \\
\hline Medication dose \& frequency & $84.2 \%$ & $78.7 \%$ & $x^{2}$ & 1 & 375 & 1.437 & -.069 & 0.231 \\
\hline Medication changes & $61.5 \%$ & $48.9 \%$ & $x^{2}$ & 1 & 375 & 5.193 & -.123 & 0.023 \\
\hline Reasons for changes & $32.1 \%$ & $18.4 \%$ & $x^{2}$ & 1 & 375 & 7.606 & -.149 & 0.006 \\
\hline Hospital plan/actions & $70.5 \%$ & $50.4 \%$ & $x^{2}$ & 1 & 375 & 14.475 & -.202 & $\begin{array}{l}< \\
0.001\end{array}$ \\
\hline Patient concerns/wishes & $8.1 \%$ & $8.5 \%$ & $x^{2}$ & 1 & 375 & .000 & .007 & 1.000 \\
\hline Information to patient & $38.5 \%$ & $24.8 \%$ & $x^{2}$ & 1 & 375 & 6.764 & -.140 & 0.009 \\
\hline GP plan \& actions & $69.7 \%$ & $53.2 \%$ & $x^{2}$ & 1 & 375 & 9.591 & -.166 & 0.002 \\
\hline Acronyms (unexplained) & $78.2 \%$ & $86.5 \%$ & $x^{2}$ & 1 & 375 & 3.482 & .103 & 0.062 \\
\hline Medical jargon (unexplained) & $71.8 \%$ & $84.4 \%$ & $x^{2}$ & 1 & 375 & 7.095 & .144 & 0.008 \\
\hline
\end{tabular}

${ }^{*} D f$. degrees of freedom

revealed that "unsuccessful" letters may contain unexplained uncommon acronyms or jargon and/or actions GPs deemed inappropriate or unreasonable (e.g. requests for GPs to chase hospital results).

Although guidelines [37, 38, 57] recommend unexplained acronyms and jargon should be avoided or at least minimised, they were identified in the majority of the sample. This poses a substantial barrier in terms of letter accessibility for patients and GPs not familiar with the specialty; this is an important issue in light of current good practice which recommends copying letters to patients [36, 37].

\section{Strengths and limitations}

The sample size was large enough to identify common drivers for GP assessed "successful" letters but small enough for qualitative analyses of all GP comments. By asking GPs to select letters that were no more than 3 weeks' old at the time of selection, we aimed to improve participant recall and reduce biasing of the sample through GPs selecting particularly memorable (either markedly "successful" or "unsuccessful") historical letters. Selecting "successful" and "unsuccessful" cases acted as a stimulus for participants to provide their views on how written discharge communications could be improved. An advantage of the sampling strategy was maximisation of variation. As planned, the letter sample exhibited diversity particularly in relation to reason for admission, and specialties. However, a limitation of this process was that it did not provide information on the average quality of National Health Service (NHS) discharge letters "typically" received in General Practice. Hence, it was not the aim of this study to describe what proportion of letters received by GPs in the setting studied are "successful" or "unsuccessful".

Although the study was limited to a small geographical area, it is likely that the views about what constitutes a successful letter are widely generalizable. However, generalisability is limited by the exclusion criteria [27] i.e. certain categories of hospital discharge (e.g. related to children, mental health problems) were excluded. Research involving these excluded groups as well as a wider range of specialist settings is needed to understand discharge summary quality in other settings. Further research is also needed to determine if patient level characteristics such as polypharmacy, multimorbidity, age, and hospital length of stay influence the quality of discharge letters.

Content analysis was strengthened by the systematic approach; each document was subjected to the same categorisation criteria, and the criteria themselves were justifiable, grounded in national standards. Our content analysis was limited by the binary codes "successful" and "unsuccessful" which may have oversimplified complex 
Table 6 Top 25 frequency results for sub-corpora comment content words

\begin{tabular}{|c|c|c|c|c|c|c|c|}
\hline \multicolumn{4}{|c|}{ "Successful" letter comments sub-corpus } & \multicolumn{4}{|c|}{ “Unsuccessful” letter comments sub-corpus } \\
\hline Rank & $\begin{array}{l}\text { No. of } \\
\text { hits }\end{array}$ & $\begin{array}{l}\text { Relative frequency (per 10,000 } \\
\text { words) }\end{array}$ & $\begin{array}{l}\text { Content } \\
\text { word }\end{array}$ & Rank & $\begin{array}{l}\text { No. of } \\
\text { hits }\end{array}$ & $\begin{array}{l}\text { Relative frequency (per 10,000 } \\
\text { words) }\end{array}$ & $\begin{array}{l}\text { Content } \\
\text { word }\end{array}$ \\
\hline 1 & 157 & 750 & clear & 1 & 41 & 151 & GP \\
\hline 2 & 53 & 253 & follow & 2 & 40 & 148 & follow \\
\hline 3 & 50 & 239 & plan & 3 & 37 & 136 & diagnosis \\
\hline 4 & 44 & 210 & diagnosis & 4 & 36 & 133 & patient \\
\hline 5 & 38 & 182 & good & 5 & 32 & 118 & discharge \\
\hline 6 & 38 & 182 & summary & 6 & 29 & 107 & medication \\
\hline 7 & 35 & 167 & discharge & 7 & 26 & 96 & summary \\
\hline 8 & 34 & 162 & GP & 8 & 23 & 85 & clear \\
\hline 9 & 33 & 158 & information & 9 & 22 & 81 & unclear \\
\hline 10 & 26 & 124 & medication & 10 & 21 & 77 & information \\
\hline 11 & 21 & 100 & detailed & 11 & 20 & 74 & poor \\
\hline 12 & 20 & 96 & investigations & 12 & 18 & 66 & letter \\
\hline 13 & 20 & 96 & medications & 13 & 15 & 55 & advice \\
\hline 14 & 19 & 91 & treatment & 14 & 14 & 52 & hospital \\
\hline 15 & 18 & 86 & given & 15 & 13 & 48 & handwritten \\
\hline 16 & 18 & 86 & management & 16 & 12 & 44 & admission \\
\hline 17 & 17 & 81 & action & 17 & 12 & 44 & dose \\
\hline 18 & 16 & 76 & changes & 18 & 10 & 37 & medications \\
\hline 19 & 16 & 76 & concise & 19 & 10 & 37 & plan \\
\hline 20 & 16 & 76 & history & 20 & 10 & 37 & started \\
\hline 21 & 15 & 72 & clearly & 21 & 9 & 33 & action \\
\hline 22 & 13 & 62 & advice & 22 & 9 & 33 & blood \\
\hline 23 & 13 & 62 & patient & 23 & 9 & 33 & details \\
\hline 24 & 12 & 20 & admission & 24 & 9 & 33 & Indication \\
\hline 25 & 12 & 20 & details & 25 & 9 & 33 & investigations \\
\hline
\end{tabular}

or borderline cases and impacted statistical comparisons. Content coding was also categorical, depending on a feature being present in the letter or not. Furthermore, we were not able to link the discharge summaries to the wider medical record directly, the content coding therefore could not account for counterfactual information. For some features, absence of inclusion may reflect that the element of content (e.g. medication change or investigation) was not applicable to the care that the patient had received. However, without this being stated within the letter, this could not be determined. Generally, if the reason for absence was clear (e.g. letter stated that no medication changes were made), than this was coded as feature presence whereas if it was unclear or entirely missing from the letter than this was coded as feature absence. Additionally, the content analysis was not exhaustive of all aspects of discharge letters; outpatient clinics and emergency department discharge letters were excluded in order to reduce the effect of confounding factors. Future research should consider those categories and elements which have not been covered here. The effect (or not) of physician experience on letter quality warrants further investigation but would require a very large sample size in order to generate statistically significant findings about professional roles that rarely write discharge summaries.

The hospital clinician survey response rate of 14.9\% was below the target of 50\%. The survey target response rate was based on previous relevant survey studies [58, 59], although studies were found which had lower rates closer to our final figure: 19\% [60], 13\% [61]. Possible factors which reduced the hospital clinician response rate were: time constraints, survey advertisement strategy, junior doctor rotations, delays between writing letter and receiving survey.

GPs and hospital clinicians did not view each other's letter gradings and comments. This was a strength in that hospital clinician recruitment and participation was 
Table 7 Summary of GP comment analysis findings

\begin{tabular}{|c|c|}
\hline Successful letter comments & Unsuccessful letter comments \\
\hline $\begin{array}{l}\text { Discharging physician details } \\
\text { - Name of responsible consultant and discharging physician and their } \\
\text { role } \\
\text { Clinical summary elements } \\
\text { - Diagnosis clear } \\
\text { - Clear clinical summary } \\
\text { - Clear results and interpretations of investigations/tests clearly recorded } \\
\text { - Treatment given in hospital clear } \\
\text { - Clear reason for admission } \\
\text { - Clear history } \\
\text { Follow up or actions } \\
\text { - Clear follow up \& management plan } \\
\text {-Clear action plan to include appropriate actions for GP and why } \\
\text { - Follow up arranged } \\
\text { - If relevant, appointments organised } \\
\text {-Clearly stated if no follow up or further action is required } \\
\text { Medication information } \\
\text { - Clear medication changes \& why } \\
\text { - Medication changes highlighted in GP action so not missed } \\
\text { - Explicit if no medications changed } \\
\text { - Advised medication monitoring and recommendations moving } \\
\text { forward } \\
\text { Patient communication } \\
\text { - Information given to patient is clear } \\
\text { Letter style } \\
\text { - Lnformation relevant and "concise" } \\
\text { - Ather } \\
\text { - All informible or readable }\end{array}$ & $\begin{array}{l}\text { Discharging physician details } \\
\text { - No discharging physician name and position } \\
\text { Clinical summary elements } \\
\text { - No diagnosis or no clear diagnosis } \\
\text { - No details of treatment (given and/or planned) } \\
\text { - No indication of tests carried out or results } \\
\text { - No information about reason for admission } \\
\text { - Cause of admission not addressed } \\
\text { Follow up or actions } \\
\text { - No advice to GP for ongoing management } \\
\text { - No or unclear follow up plan or arrangements } \\
\text { - GP asked to make referrals hospital should have } \\
\text { - Advice to GP described as vague and not helpful } \\
\text { - Request for GP to chase results } \\
\text { - Unrealistic GP blood test requests (<1 week) } \\
\text { Medication information } \\
\text { - No medication details } \\
\text { - Not clear why medication changed } \\
\text { - Says no GP action but changes made to medications } \\
\text { - No medication dosing or duration } \\
\text { - GP asked to prescribe specialist-only medication } \\
\text { - Medication not dispensed } \\
\text { Patient communication } \\
\text {-Information given to patient not indicated or no information given to } \\
\text { patient } \\
\text { Letter style } \\
\text { - Use of uncommon acronyms without explanation } \\
\text { - Illegible/ letter is handwritten and difficult to read } \\
\text { Other } \\
\text { - No discharge date } \\
\text { - No patient address } \\
\text { - Incorrect information in summary } \\
\text { - Key details omitted e.g. antibiotic given } \\
\text { - Multiple addendums } \\
\text {-Letter arrived late to GP/took a long time }\end{array}$ \\
\hline
\end{tabular}

not biased by the GP's assessment. However, it did mean that feedback on the letter from the primary care perspective could not be provided to participating hospital clinicians on an individual basis; this could have been useful for professional development, and is a potential avenue for future work.

\section{Implications for practice}

Missing information on discharge summaries could lead to errors in clinical care and might also affect patients' understanding of what happened to them in hospital. The findings from this study indicate that important information is missing from many discharge summaries, including those graded "successful". This is despite standards stipulating mandatory content of discharge summaries to include the US Joint Commission discharge summary standards [62, 63] and the UK Royal College of Physicians [35, 64] guidelines as well as the more recent PRSB eDischarge standard [40, 65] which allows Systematized Nomenclature of Medicine Clinical Terms (SNOMED) [66] coded information to be transferred directly between hospitals and GPs. Our findings suggest that failure for hospitals and clinicians to uniformly implement discharge letter guidance into practice is continuing to contribute to unsuccessful communication between hospitals and general practice; this has implications for continuity of care and patient safety. We make the following suggestions to increase uptake of guidelines into practice:

1. Promotion of this work and related studies to highlight the importance of guidelines for discharge summary creation and to build the evidence base behind guidelines

2. Involving patients in discharge communication

The elements of a "successful" letter identified in this study largely fit with PRSB discharge guidelines [40, 65] but also indicated scope for further development around some of the areas to include GP actions, treatment, and writing style. Delegation to GPs of following up on results from investigations undertaken while in hospital may create inter-professional tension $[67,68]$, but this practice continues despite national guidance to the contrary [69]. "Clear" was the number one content word within "successful" comments and so the importance of clarity and style to GPs is evident. GPs highlighted issues within the sample letters in regard to unexplained 
acronyms and uncommon jargon which can pose a clinical risk. This suggests a need for greater emphasis on the writing style within discharge summaries. Through identifying contributing factors towards "unsuccessful" letters, the research highlights a need for increased training and support for clinicians on letter writing as well as organisational initiatives such as evaluating implementation of guidelines [70] and ongoing audit to ensure that the quality of discharge letters minimises patient risk.

\section{Conclusions}

This study examined the content and quality of discharge letters in respect of UK guidelines and standards, although the recommendations may have relevance to other healthcare systems. This study has highlighted barriers to producing high quality discharge summaries; these may be addressed through training and organisational initiatives. The sampled discharge summaries tended to lack components considered key by GPs, particularly information regarding what the patient has been told and GP actionable components. Poor discharge communication carries risks and represents a possible missed opportunity for effective communication and safe patient transition into the community setting. Letter quality hinged upon component inclusion and the clarity and relevance of the details to the specific case. In conclusion, this study outlines shortcomings of discharge summaries and ways in which discharge communication may be improved.

\section{Abbreviations}

ACP: Advanced Clinical Practitioner; GP: General Practitioner (UK family or primary care physician); LL: Log Likelihood; NHS: (UK) National Health Service; PRSB: The Professional Record Standards Body; SNOMED: Systematized Nomenclature of Medicine Clinical Terms; SPSS: Statistical Package for the Social Sciences; UK: United Kingdom

\section{Supplementary Information}

The online version contains supplementary material available at https:/doi. org/10.1186/s12913-021-06345-z.

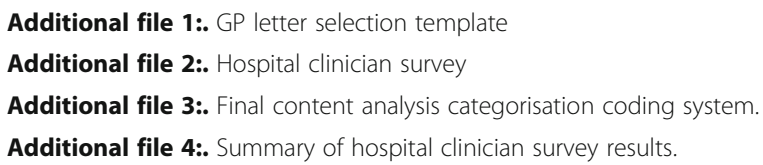

\section{Acknowledgements}

The authors would like to thank the GPs and hospital clinicians who participated in the study. We would like to thank all the funders for their support. We would also like to thank the West Midlands Clinical Research Network primary care specialty team for their support with research recruitment and setting up practice sites. Finally, we would like to thank the Institute of Advanced Study at the University of Warwick for their support during the write-up of this paper.

\section{Authors' contributions}

KW and RS drafted the manuscript which was then critically revised for intellectual content by JD, ES and SS. KW, ES, SS and JD substantially contributed to the design and conception of the work and all authors collaborated on data interpretation. All authors approved the final manuscript version for publication and agree to be accountable for all aspects of the work. The authors read and approved the final manuscript.

\section{Funding}

This research formed part of a PhD which was supported by the Economic and Social Research Council (ESRC) [grant number ES/J500203/1] and Clinical Commissioning Groups (CCGs) of Coventry \& Rugby and South Warwickshire. Funding for the open access charges for publication of this manuscript was provided by the UKRI fund.

\section{Availability of data and materials}

The majority of datasets supporting the conclusions of this article are included within the article (and its additional files). However, the full datasets generated during the current study are not publicly available due to the sensitive and identifiable nature of the data. Despite names and other identifiers being removed, the in-depth nature of the discharge letters may mean that patients could be identified. The anonymised survey results are found in additional file 4 . Summaries of data characteristics have been provided for relevant data sets.

\section{Declarations}

Ethics approval and consent to participate

Ethics approval was granted by the UK NHS Health Research Authority in July 2017 (Integrated Research Application System ID: 219871). The study was given a favourable ethics approval opinion from West Midlands Coventry \& Warwickshire Research Ethics Committee in July 2017 (reference: 17/WM/0170). Survey participants consented to take part in writing via completed surveys.

\section{Consent for publication}

Not applicable.

\section{Competing interests}

The authors declare that they have no competing interests.

\section{Author details}

${ }^{1}$ Unit of Academic Primary Care, Warwick Medical School, University of Warwick, Coventry, England CV4 7AL, UK. ${ }^{2}$ Applied Linguistics, University of Warwick, Coventry, UK.

Received: 21 October 2020 Accepted: 3 April 2021

Published online: 15 April 2021

\section{References}

1. Kripalani S., Jackson A.T., Schnipper J.L., Coleman E.A. Promoting effective transitions of care at hospital discharge: a review of key issues for hospitalists. J Hosp Med 2007;2(5):314-323. Available from: https://www. journalofhospitalmedicine.com/jhospmed/article/127279/transitions-carehospital-discharge [Accessed: 11/03/2021], DOl: https://doi.org/10.1002/ jhm.228.

2. Spencer R.A., Spencer S.E.F., Rodgers S., et al. Processing of discharge summaries in general practice: a retrospective record review. Br J Gen Prac. 2018;68(673):e576-ee85. Available from: https://bjgp.org/content/bjgp/68/ 673/e576.full.pdf. [Accessed 6 Oct 2020].

3. Williams H., Edwards, A., Hibbert, P. et al. Harms from discharge to primary care: mixed methods analysis of incident reports. Br J Gen Pract 2015; 65(641):e829-ee37. Available from: https://bjgp.org/content/bjgp/65/641/ e829.full.pdf [Accessed: 30/09/2020].

4. Alqenae F.A., Steinke, D., Keers, R.N. Prevalence and nature of medication errors and medication-related harm following discharge from hospital to community settings: a systematic review. Drug Saf 2020;43(6):517-537. Available from: https://www.ncbi.n/m.nih.gov/pmc/articles/PMC7235049/ [Accessed: 30/09/2020], DOI: https://doi.org/10.1007/s40264-020-00918-3.

5. Foronda C., MacWilliams, B., McArthur, E. Interprofessional communication in healthcare: an integrative review. Nurse Educ Pract 2016;19(1):36-40. Available from: https://www.sciencedirect.com/science/article/pii/S1471 595316300208 [Accessed: 04/09/2020], DOl: https://doi.org/10.1016/j.nepr.2 016.04.005. 
6. Scotten M., Manos, E.L., Malicoat, A., Paolo, A.M. Minding the gap: Interprofessional communication during inpatient and post discharge chasm care. Patient Educ Couns 2015;98(7):895-900. Available from: https:// www.sciencedirect.com/science/article/pii/S0738399115001007 [Accessed: 04/09/2020], DOI: https://doi.org/10.1016/j.pec.2015.03.009.

7. Esmail A., Neale, G., Elstein, M., Firth-Cozens, J., Davy, C., Vincent, C. . A report for the Manchester Centre for healthcare management. Patient safety: lessons from litigation 2004.

8. Carson-Stevens A., Hibbert P., Williams H., Evans H.P., Cooper A., Rees P. Deakin A., Shiels E., Gibson R., Butlin A., Carter B., Luff D., Parry G., Makeham M. - McEnhill P., Ward H.O., Samuriwo R., Avery A., Chuter A., Donaldson L., Mayor S., Panesar S., Sheikh A., Wood F., Edwards A. Characterising the nature of primary care patient safety incident reports in the England and Wales National Reporting and learning system: a mixed-methods agenda-setting study for general practice. Health Serv Deliv Res 2016 https://pubmed.ncbi. nlm.nih.gov/27656729/. Available from: https://pubmed.ncbi.nlm.nih.gov/2 7656729/ [Accessed: 24/6/20], 4, 27, 1, 76, DOl: https://doi.org/10.3310/ hsdr04270.

9. Maxwell K., Harrison J., Scahill S., et al. Identifying drug-related problems during transition between secondary and primary care in New Zealand. Int J Pharm Pract. 2013; 21(5): 333-336. Available from: https://doi.org/10.1111/ ijpp.12013 [Accessed: 10/06/20].

10. Grimes T.C., Duggan C.A., Delaney T.P., Graham I.M., Conlon K.C., Deasy E., Jago-Byrne M.C., O' Brien P. Medication details documented on hospital discharge: cross-sectional observational study of factors associated with medication non-reconciliation. Br J Clin Pharmacol 2011;71(3):449-457. Available from: https://doi.org/10.1111/j.1365-2125.2010.03834.x [Accessed: 24/6/20].

11. Horwitz L.I., Jenq G.Y., Brewster U.C., Chen C., Kanade S., van Ness P.H., Araujo K.L.B., Ziaeian B., Moriarty J.P., Fogerty R.L., Krumholz H.M. Comprehensive quality of discharge summaries at an academic medical center. J Hosp Med (Online) 2013;8(8):436-443. Available from: https://doi.org/10.1002/jhm.2021 [Accessed: 24/6/20].

12. Schwarz C.M., Hoffmann M., Schwarz P., et al. A systematic literature review and narrative synthesis on the risks of medical discharge letters for patients' safety. BMC Health Serv Res. 2019;19(1):158. Available from: https://doi.org/1 0.1186/s12913-019-3989-1. [Accessed 6 Oct 2020].

13. Lenert L.A., Sakaguchi F.H., Weir C.R. Rethinking the discharge summary: a focus on handoff communication. Acad Med. 2014; 89(3): 393-398. [Accessed: 10/06/20]

14. Alderton M., Callen J. Are general practitioners satisfied with electronic discharge summaries? Health Inform Manag J 2007;36(1):7-12. Available from: https://pubmed.ncbi.nlm.nih.gov/18195392/ [Accessed: 24/6/20], DOI: https://doi.org/10.1177/183335830703600102.

15. Groene R.O., Orrego C., Sunol R., et al. "It's like two worlds apart": an analysis of vulnerable patient handover practices at discharge from hospital. BMJ Qual Saf 2012;21 Suppl 1:i67-i75. Available from: https://qualitysafety.bmj. com/content/21/Suppl_1/i67.long [Accessed: 10/06/20], DOl: https://doi. org/10.1136/bmjgs-2012-001174.

16. Grimes T., Delaney T., Duggan C., Kelly J.G., Graham I.M. Survey of medication documentation at hospital discharge: implications for patient safety and continuity of care. Ir J Med Sci 2008;177(2):93-97. Available from: https://pubmed.ncbi.nlm.nih.gov/18414970/ [Accessed: 24/6/20], DOI: https://doi.org/10.1007/s11845-008-0142-2.

17. Polyzotis P.A., Suskin N., Unsworth K., Reid R.D., Jamnik V., Parsons C., Grace S. L. Primary care provider receipt of cardiac rehabilitation discharge summaries: are they getting what they want to promote long-term risk reduction? Circul Cardiovasc Qual Outcomes 2013;6(1):83-89. Available from: https://doi.org/10.1161/CIRCOUTCOMES.112.967539 [Accessed: 24/6/ 20].

18. Kripalani S., LeFevre F., Phillips C.O., Williams M.V., Basaviah P., Baker D.W. Deficits in communication and information transfer between hospital-based and primary care physicians: implications for patient safety and continuity of care. JAMA. 2007;297(8):831-841. Available from: https://doi.org/10.1001/ jama.297.8.831 [Accessed: 24/6/20].

19. Perren A., Previsdomini M., Cerutti B., Soldini D., Donghi D., Marone C. Omitted and unjustified medications in the discharge summary. Qual Saf Health Care 2009;18(3):205-208. Available from: https://doi.org/10.1136/ qshc.2007.024588 [Accessed: 24/6/20].

20. Uitvlugt E.B., Siegert C.E., Janssen M.J., et al. Completeness of medicationrelated information in discharge letters and post-discharge general practitioner overviews. Int J Clin Pharm 2015;37(6):1206-1212. Available from: https://pubmed.ncbi.n/m.nih.gov/26337836/ [Accessed: 24/6/20], DOl: https://doi.org/10.1007/s11096-015-0187-z.

21. Wernick M., Hale P., Anticich N., Busch S., Merriman L., King B., Pegg T. A randomised crossover trial of minimising medical terminology in secondary care correspondence in patients with chronic health conditions: impact on understanding and patient reported outcomes. Intern Med J 2016;46(5): 596-601. Available from: https://pubmed.ncbi.n/m.nih.gov/26968750/ [Accessed: 24/6/20], DOl: https://doi.org/10.1111/imj.13062.

22. Flink M., Bergenbrant Glas S., Airosa F., et al. Patient-centered handovers between hospital and primary health care: an assessment of medical records. Int J Med Inform. 2015; 84(5): 355-362. [Accessed: 10/06/20].

23. Pesko M.F., Gerber, L. M., Peng, T. R., Press, M. J. Home health care: nursephysician communication, patient severity, and hospital readmission. Health Serv Res 2018;53(2):1008-1024. Available from: https://pubmed.ncbi.nlm.nih. gov/28217974/ [Accessed: 11/06/20], DOl: https://doi.org/10.1111/14756773.12667.

24. Considine J., Berry, D., Sprogis, S.K., Newnham, E., Fox, K., Darzins, P., Rawson, $H_{\text {., }}$ Street, M. Understanding the patient experience of early unplanned hospital readmission following acute care discharge: a qualitative descriptive study. BMJ Open 2020;10(5):e034728. Available from: https:// bmjopen.bmj.com/content/bmjopen/10/5/e034728.full.pdf [Accessed: 11/ 06/20], DOl: https://doi.org/10.1136/bmjopen-2019-034728.

25. Mehta R.L., Baxendale B., Roth K., Caswell V., le Jeune I., Hawkins J., Zedan H., Avery A.J. Assessing the impact of the introduction of an electronic hospital discharge system on the completeness and timeliness of discharge communication: a before and after study. BMC Health Serv Res 2017;17(1): 624. Available from: https://pubmed.ncbi.nlm.nih.gov/28870188/ [Accessed: 24/6/20], DOl: https://doi.org/10.1186/s12913-017-2579-3.

26. NHS England. Guidance on the NHS Standard Contract requirements on discharge summaries and clinic letters and on interoperability of clinical IT systems. In: NHS, editor. 1.0 ed. ONLINE. 2018. Available from https://www. england.nhs.uk/wp-content/uploads/2018/09/interoperability-standardcontract-guidance.pdf

27. Weetman K., Dale J., Scott E., et al. The discharge communication study: research protocol for a mixed methods study to investigate and triangulate discharge communication experiences of patients, GPs, and hospital professionals, alongside a corresponding discharge letter sample. BMC Health Serv Res. 2019; 19(1): 825. Available from: https://doi.org/10.1186/s12 913-019-4612-1 [Accessed: 10/06/20].

28. Weetman K., Dale J., Spencer R., et al. GP perspectives on hospital discharge letters: an interview and focus group study. BJGP Open 2020. Available from: https://bjgpopen.org/content/4/2/bjgpopen20X101031 [Accessed: 10/06/20]

29. Weetman K., Dale J., Scott E., et al. Adult patient perspectives on receiving hospital discharge letters: a corpus analysis of patient interviews. BMC Health Serv Res. 2020; 20(1): 537. Available from: https://doi.org/10.1186/s12 913-020-05250-1 [Accessed: 24/6/20].

30. Miller M. Statistics and measurement concepts with OpenStat. New York: Springer; 2013. https://doi.org/10.1007/978-1-4614-5743-5.

31. De Vaus DA. Surveys in social research. Routledge Ltd: M.U.A; 2013.

32. Hsieh H., Shannon, S.E. Three approaches to qualitative content analysis. Qual Health Res. 2005;15(9):1277-1288. Available from: https://journals.sa gepub.com/doi/abs/10.1177/1049732305276687. [Accessed 6 Oct 2020].

33. Sackley C.M., Pound K. Stroke patients entering nursing home care: a content analysis of discharge letters. Clin Rehabil 2002;16(7):736-740. Available from: https://journals.sagepub.com/doi/abs/10.1191/0269215502 cr535oa [Accessed: 11/06/2020].

34. Mayring P. Qualitative Content Analysis Qualitative Social Research 2000;1(2). Available from: https://nbn-resolving.de/urn:nbn:de:0114-fqs0002204 [Accessed: 10/06/20].

35. Royal College of Physicians. Standards for the clinical structure and content of patient records. 2013. Available from https://www.rcplondon.ac.uk/ projects/outputs/standards-clinical-structure-and-content-patient-records

36. Department of Health. The NHS plan: a plan for investment a plan for reform. London: HMSO; 2000. Available from https://webarchive.nationala rchives.gov.uk/20121102184216/http://www.dh.gov.uk/en/Publicationsa ndstatistics/Publications/PublicationsPolicyAndGuidance/DH_4002960

37. Department of Health. Copying letters to patients: good practice guidelines. 2003. Available from https://webarchive.nationalarchives.gov.uk/2012050403 0618/.https://www.dh.gov.uk/prod_consum_dh/groups/dh_digitalassets/ @dh/@en/documents/digitalasset/dh_4086054.pdf 
38. National Institute for Health and Care Excellence (NICE). Patient experience in adult NHS services: improving the experience of care for people using adult NHS services 2012. Available from: https://www.nice.org.uk/guidance/ cg138.

39. NHS Digital. The PRSB Standards for the Structure and Content of Health and Care Records. Professional Record Standards Body (PRSB); 2018. Available from https://theprsb.org/standards/healthandcarerecords/

40. Professional Record Standards Body. Implementation guidance report eDischarge standard. Better records for better care. 2019. Available from https://theprsb.org/standards/healthandcarerecords/

41. Centre for Reviews and Dissemination. Systematic Reviews: CRD's guidance for undertaking reviews in health care. 2008. Available from https://www. york.ac.uk/media/crd/Systematic_Reviews.pdf

42. Stewart A, Akunjee M. Basic statistics and epidemiology : a practical guide. 4th ed. London: Chapman and Hall/CRC; 2018. https://doi.org/10.1201/ 9781315383286.

43. Pallant J. SPSS survival manual: a step by step guide to data analysis using IBM SPSS. 6th ed. Berkshire: Open University Press; 2016.

44. McEnery T, Wilson A. Corpus linguistics. Manchester: Edinburgh University Press; 1996.

45. Sinclair J. Corpus, concordance, collocation. Oxford: Oxford University Press; 1991.

46. Kennedy G. An introduction to corpus linguistics. London: Routledge; 2014. https://doi.org/10.4324/9781315843674.

47. Biber D, Conrad S, Reppen R. Corpus linguistics: investigating language structure and use. Cambridge: Cambridge University Press; 1998. https://doi. org/10.1017/CBO9780511804489.

48. Brookes G., Baker P. What does patient feedback reveal about the NHS? A mixed methods study of comments posted to the NHS choices online service. BMJ Open 2017;7(4):e013821. Available from: https://bmjopen.bmj. com/content/bmjopen/7/4/e013821.full.pdf [Accessed: 10/06/20], DOl: https://doi.org/10.1136/bmjopen-2016-013821.

49. Wiskin C., Duffy J., Weetman K., Skelton J., Swindells C. Mindset, confidence and skill: the impact of a development intervention. Brit J Healthc Manag 2016;22(6):315-324. Available from: https://doi.org/10.12968/bjhc.2016.22. 6.315 [Accessed: 10/06/20].

50. Anthony L. Antconc. 3.5.7 ed. Tokyo: Waseda University; 2018. Available from https://www.laurenceanthony.net/software

51. Conover WJ. Practical nonparametric statistics. 3rd ed. New York. Chichester: John Wiley; 1999.

52. Sprent $P$, Smeeton NC. In: Raton B, editor. Applied nonparametric statistical methods. 4th ed. Boca Raton: Chapman and Hall/CRC; 2007.

53. Guest G, MacQueen KM, Namey EE. Applied thematic analysis. Los Angeles: Sage; 2011.

54. Braun V, Clarke V. Thematic analysis. In: Cooper H, Camic PM, Long DL, Panter AT, Rindskopf D, Sher KJ, editors. APA handbook of research methods in psychology. Research designs: Quantitative, qualitative, neuropsychological, and biological. 2. United States: American Psychological Association; 2012. p. 57-71.

55. Landis J.R., Koch, G.G. The measurement of observer agreement for categorical data. Biometrics. 1977 https://pubmed.ncbi.n/m.nih.gov/843 571/:159-74. Available from: https://pubmed.ncbi.nlm.nih.gov/843571/ [Accessed: 10/06/20], 33, 1, 174, DOl: https://doi.org/10.2307/2529310.

56. Feinstein A.R., Cicchetti D.V. High agreement but low kappa: I. The problems of two paradoxes. J Clin Epidemiol. 1990; 43(6): 543-549.[Accessed: 10/06/20].

57. The Academy of Medical Royal Colleges. Please, write to me: Writing outpatient clinic letters to patients. 2018. Available from https://www.aomrc. org.uk/reports-guidance/please-write-to-me-writing-outpatient-clinic-lettersto-patients-guidance/

58. Clarke R.T., Pitcher A., Lambert T.W., Goldacre M.J. UK doctors' views on the implementation of the European working time directive as applied to medical practice: a qualitative analysis. BMJ Open 2014;4(2): e004390. Available from: https://bmjopen.bmj.com/content/bmjopen/4/2/e004390. full.pdf [Accessed: 10/06/20], DOl: https://doi.org/10.1136/bmjopen-2013004390

59. Connolly B., Douiri A., Steier J., et al. A UK survey of rehabilitation following critical illness: implementation of NICE clinical guidance 83 (CG83) following hospital discharge. BMJ Open. 2014; 4(5): e004963-e. Available from: https:// www.ncbi.n/m.nih.gov/pubmed/24833691 [Accessed: 10/06/20].

60. Hepburn S., Banks R.E., Thompson D. Protein Biomarker Research in UK Hospital Clinical Biochemistry Laboratories: A Survey of Current Practice and
Views. Clin Biochem Rev. 2014; 35(2): 115-133. Available from: https://www. ncbi.n/m.nih.gov/pubmed/25210209 [Accessed: 10/06/20].

61. Mittal T.K., Cleghorn C.L., Cade J.E., et al. A cross-sectional survey of cardiovascular health and lifestyle habits of hospital staff in the UK: Do we look after ourselves? Eur J Prevent Cardiol. 2018; 25(5): 543-550. Available from: https://www.ncbi.nlm.nih.gov/pubmed/29198137 [Accessed: Protein Biomarker Research in UK Hospital Clinical Biochemistry Laboratories: A Survey of Current Practice and Views].

62. Joint Commission on Accreditation of Healthcare Organisations. The Targeted Solutions Toolkit. 2018. Available from https://www.centerfortra nsforminghealthcare.org/tst.aspx.

63. Agency for Healthcare Research and Quality. Re-Engineered Discharge Toolkit. 2017. Available from: https://www.ahrq.gov/professionals/systems/ hospital/red/toolkit/index.html [Accessed: 4/7/18].

64. Royal College of Physicians. Hospital Discharge Audit Tool. Health Informatics Unit. 2011. Available from https://www.rcplondon.ac.uk/file/206/ download?token=_XJ_6BbX

65. Professional Records Standards Body. eDischarge summary standard. 2020. Available from https://theprsb.org/standards/edischargesummary/

66. SNOMED. SNOMED International 2020. Available from: https://www. snomed.org/.

67. Jones C.D., Vu M.B., O'Donnell C.M., et al. A failure to communicate: a qualitative exploration of care coordination between hospitalists and primary care providers around patient hospitalizations. J Gen Intern Med 2015;30(4):417-424. Available from: https://doi.org/10.1007/s11606-014-3056x [Accessed: 24/6/20].

68. Spencer R.A., Rodgers S., Salema N., et al. Processing discharge summaries in general practice: a qualitative interview study with GPs and practice managers. BJGP Open. 2019;3(1):bjgpopen18X101625. Available from: https://bjgpopen.org/content/bjgpoa/3/1/bjgpopen18X101625.full.pdf. [Accessed 6 Oct 2020].

69. NHS England. Standards for the communication of patient diagnostic test results on discharge from hospital. 2016. Available from https:// improvement.nhs.uk/uploads/documents/discharge-standards-march-16.pdf

70. Academy of Medical Royal Colleges. What are the key success factors for their development and implementation? College Guidelines 2017. Available from https://www.aomrc.org.uk/wp-content/uploads/2017/05/College_ Guidelines_0517-1.pdf

\section{Publisher's Note}

Springer Nature remains neutral with regard to jurisdictional claims in published maps and institutional affiliations.
Ready to submit your research? Choose BMC and benefit from:

- fast, convenient online submission

- thorough peer review by experienced researchers in your field

- rapid publication on acceptance

- support for research data, including large and complex data types

- gold Open Access which fosters wider collaboration and increased citations

- maximum visibility for your research: over $100 \mathrm{M}$ website views per year

At BMC, research is always in progress.

Learn more biomedcentral.com/submissions 